are available. Unesco should commission a critical study of the potentialities of the apparatus described in the Federation of International Documentation Manual, indicating its value and limitations for the main uses in libraries and documentation work. $\mathrm{He}$ also recommends the issue of international lists of translations of periodical articles, using the best available mechanical techniques, the establishment in each country or suitable region of at least one punched-card unit with photo-offset equipment for the production of the lists and indexes as needed, and the compilation of a manual of the practice and organization of such services, as well as the subsidizing of research on the production of equipment more suited for the production of these lists. Unesco should also organize an international conference of experts from all patent offices to discuss mechanization, and publish in its proceedings an authoritative summary of the state of present knowledge in this field. In collaboration with the International Federations in Bibliography, Pure and Applied Sciences and Social Scionces, Unesco should also establish and maintain the administrative procedures required to link national and international services in the field of communication of knowledge.

With regard to the older techniques, Dr. Coblans suggests that international organizations should arrange to send their documents to the relevant abstracting periodicals, that in each country there should be one overall social seience centre to receive lists of specialists, research in progress and informa. tion about conferences and the location of unpublished material, and that the Unesco Social Science Clearing House should co-ordinate the activities of all such centres. He also advocates a long-term study of the adequacy of the scientific periodical as a method of communication, a survey, with the help of the Abstracting Board of the International Council of Scientific Unions, of the extent to which the major abstracting and indexing services in the natural sciences cover articles in annual reviews and technical research reports, the issuo of regular lists of published proceedings of international conferences, and a conference on the production and distribution of literature on nuclear energy.

\section{Writing and Searching}

Two recent articles in Research merit the close attention of every postgraduate research student and young research worker. The first, entitled "A Note on the Writing of Scientific Papers and Theses" (10, 168 ; May 1957), contains the substance of a lecture delivered at the Atomic Energy Research Establishment, Harwell, by Dr. W. Hume-Rothery. Though it is usual to give constant supervision during the course of a student's research work, very rarely is training given in the important task of writing and preparation of the subsequent report for publication. It is only too well known how poor is the presentation of many contributions to scientific journals. In his advice, Dr. Hume-Rothery adheres to traditional lines. $H_{\theta}$ gives several examples to illustrate the more common faults, emphasizes the importance of conciseness and discusses how to make a paper interesting and clear. It is recommended that experimental results should be so displayed that the reader may sco their general nature and, in addition, the exact values to within the limits of experimental accuracy. In this regard Dr. Hume-Rothery deplores the regulations of some journals against the showing of results in both tabular and diagrammatic form.

The second article, "Searching the Literature", by M. A. Short (10, 313 ; August 1957), although concerned specifically with the literature of physical and inorganic chemistry, nevertheless contains much of value to all chemists and physicists. In making the survey of the relevant literature before a research project is undertaken, there are two conflicting factors-speed and thoroughness-and some balance has to be struck between them. Dr. Short provides an excellent working guide for the ordinary research worker on how best to go about his search systematically. The main chemical and physical libraries in London; the various abstracting journals and their coverage; and the foreign periodicals which are available in an English translation are listed, and in appendixes details are given of suggested treatises and handbooks to be consulted and the titles of the journals of major importance published in the years prior to 1875 . In conclusion, Dr. Short gives some brief but interesting advice about how to keep up to date, and how to record the information obtained from the search in an easily available form.

\section{National Institute of Agricultural Botany}

THe report of the Council of the National Institute of Agricultural Botany for the year 1956 has now been published (The Secretary, N.I.A.B., Huntingdon Road, Cambridge. 2s.). During the year under review there was some reorganization of the work, and a new section, the Multiplication Branch, is now responsible for the increase of pure stocks of seed bred by the official plant breeding institutes. These include cereals and sugar beet from the Cam. bridge Plant Breeding Institute, grasses and clovers from the Welsh Plant Breeding Station, brassicas and onions from the National Vegetable Research Station, and hybrid tomatoes from the John Innes Horticultural Institution. The remainder of the Crop Improvement Branch is now more appropriately named the Trials Branch. Some 331 acres of stock seed crops of the Aberystwyth strains of grasses and clovers were harvested by the new Multiplication Branch and a further 640 acres by the Welsh Plant Breeding Station, the newly erected herbage granary coming into use for the first time. Interim comments on forty-five cereal varieties which have been tested for two or three years are reported by the Trials Branch and an account given of its work on vegetable erops, which has included group classifications of named seed stocks of brussels sprouts and carrots. Further expansion is reported by the Seed Production Branch. 63,000 acres of seed crops were approved under the cereal field approval scheme, while under that for herbage and seed certification, 90 per cent of all eligible crops of Aberystwyth strains of grasses and clovers were entered for the national comprehensive certification scheme in the first year of its operation. The total number of samples received by the Official Sced Testing Station was very similar to that of the previous year, the good harvesting conditions of 1955 being reflected in the high proportion of clover samples sent in.

\section{Transference of Rust-resistance to Bread Wheats}

IT is known that some species in the genera Agropyron and Aegilops are highly resistant to the rusts which attack wheat. One way of making 